\title{
Vitamin-A deficiency and its determinants among preschool children: a community based cross-sectional study in Ethiopia
}

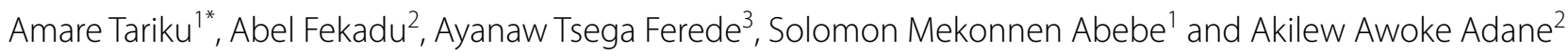

\begin{abstract}
Background: Vitamin A deficiency is the leading cause of preventable visual impairments in children. It is also an underlying cause for nearly one-fourth of global child mortality associated with measles, diarrhea, and malaria. The limited literature available in Ethiopia shows severe public health significance of vitamin-A deficiency. Hence the aim of the current study was to assess the prevalence and factors determining vitamin-A deficiency among preschool children in Dembia District, northwest Ethiopia.
\end{abstract}

Methods: A community-based cross-sectional study was conducted among preschool children of Dembia District from January to February, 2015. A multi-stage sampling, followed by a systematic sampling technique was employed to select study participants. A structured interviewer-administered questionnaire was used to collect data. Using a binary logistic regression model, multivariable analysis was fitted to identify the associated factors of vitamin-A deficiency. The adjusted odds ratio (AOR) with a $95 \%$ confidence interval was computed to assess the strength of the association, and variables with a p value of $<0.05$ in multivariable analysis were considered as statistically significant.

Results: Six hundred eighty-one preschool children were included in the study, giving a response rate of $96.5 \%$. The overall prevalence of xerophthalmia was $8.6 \%$. The result of the multivariable analysis revealed that nonattendance at the antenatal care clinic [AOR 2.65,95\% Cl (1.39,5.07)], being male [AOR 1.81, $95 \% \mathrm{Cl}(1.01,3.24)]$, and in the age group of 49-59 months [AOR 3.00, $95 \% \mathrm{Cl}(1.49,6.02)]$ were significantly associated with vitamin-A deficiency.

Conclusions: Vitamin-A deficiency is a severe public health problem in the study area. Further strengthening antenatal care utilization and giving emphasis to preschool children will help to mitigate vitamin-A deficiency in the study area.

Keywords: Xerophthalmia, Determinants, Preschool children, Ethiopia

\section{Background}

Vitamin A is an essential nutrient needed in smaller amounts for normal visual and immune functions, the maintenance of epithelial cellular integrity, growth, and development $[1,2]$. Due to their increased nutrient demand and the severity of the potential health

\footnotetext{
*Correspondence: amaretariku15@yahoo.com

${ }^{1}$ Department of Human Nutrition, Institute of Public Health, College of Medicine and Health Sciences, The University of Gondar, Gondar, Ethiopia

Full list of author information is available at the end of the article
}

consequences associated with vitamin-A deficiency (VAD), preschool children and pregnant women are considered as the most at-risk segments of the community [1]. According to the recent World Health Organization (WHO) estimate, VAD has a moderate and severe public health significance in 45 and 122 countries in the world, respectively. About one-third (33.3\%) of the world's preschool children are found with sub-clinical VAD, and $0.9 \%$ with night blindness. The highest burden of VAD occurs in Africa and southeast Asia [1]. Africa alone contributes more than one-third of the global burden of 
childhood xerophthalmia [3], according to which about $44.4 \%$ (56.4 million) and $2 \%$ of the preschool children are affected by sub-clinical VAD and night blindness, respectively.

The consequence of VAD is magnified by poverty and the higher prevalence of infectious diseases [4] and it is an underlying cause for nearly one-fourth of global child mortality from measles, diarrhea, and malaria [5]. This mortality risk worsens among children born in SubSaharan African countries, which face 16.5 and 1.8 times higher probability of dying before the age of 5 years compared to children born in developed regions and Southern Asia, respectively [6]. VAD along with measles is the major cause of preventable visual impairment in children [7]. Though VAD is a multi-casual disorder, episodes of severe disease [8-10], poor dietary intake of protein and vitamin-A rich food [10], lack of vitamin-A supplementation, poor immunization status, poor maternal awareness about vitamin-A and high parity [8,9], poor maternal education, socioeconomic status and sanitary practice, male sex, and nutritional stunting $[11,12]$ were some of the factors significantly associated with it.

The findings of the limited research done in Ethiopia reveal that, VAD is one of the major public health problems [3, 13-15], because more than one-third (37. $6 \%$ ) of the children under 5 years are suffering from subclinical VAD, 4.3-7.3 \% from night blindness, and $2.2 \%$ from Bitot's Spots [14]. In Ethiopia and other African countries, poverty, sub-optimal nutrition, insanitary living conditions, and poor health care access exacerbate the risk of developing multiple micronutrient deficiencies [16-18]. Accordingly, only half of the young children grow with optimal breastfeeding. Twenty-six percent of the young children consume vitamin-A rich foods, while only $4 \%$ receive food from at least four food groups [19].

It has been confirmed that improving the vitamin $\mathrm{A}$ status of deficient children significantly reduces the risk of mortality from measles by $50 \%$, from diarrhea by $40 \%$, and overall mortality by $25-35 \%$ [20]. Therefore, the elimination of VAD is considered a key element for improving the survival, well-being, growth, and development of children. Thus, research showing the burden and determinants of VAD is of paramount importance. However, such studies are scarce in Ethiopia, particularly in the northwestern part of the country. Therefore, this study aimed to assess the prevalence and determinants of VAD among preschool children.

\section{Methods}

\section{Study setting}

The study was conducted in Dembia District, northwest Ethiopia. The district has 45 kebeles (smallest administrative units in Ethiopia), of which 40 are rural. It has a total population of 315,903 with $260.1 / \mathrm{km}^{2}$ population density. Preschoolers comprise $5.7 \%(18,006)$ of the total population [21]. There are 10 health centers and 40 health posts in the district. Surrounded by the great Lake Tana, the district is a well-known malaria endemic area. The residents are by and large surplus producing farmers cultivating mainly cereals, legumes, and spices [22]. According to the 2015 District Health Office report, the overall immunization coverage is $81.5 \%$ while it is $77.1 \%$ for measles. Furthermore, the coverage for Rota Virus- 1 and Rota Virus-2 immunization is 83.1 and $77.1 \%$, respectively, and incredibly, it is $98 \%$ for vitamin-A supplementation.

\section{Study design and participants}

A community-based cross-sectional study was conducted from January to February, 2015. All preschool children who lived in the district for at least 6 months were included in the study.

\section{Sample size and sampling procedure}

The minimum sample size was determined using the single population proportion formula with the following assumptions: $5.8 \%$ expected prevalence of xerophthalmia [15], $95 \%$ confidence level, and $2.5 \%$ margin of error (d). Finally, a minimum sample size of 706 was obtained after anticipating a $10 \%$ non-response rate and the adjusting design effect of two. A multi-stage sampling followed by a systematic sampling technique was employed to reach the study subjects. Initially, nine representative kebeles in the district (one urban and eight rural) were selected using the lottery method. The total number of eligible preschool children living in the kebeles were obtained from the local administration and used to calculate the sampling fraction (k). After a proportional allocation to each kebele, the systematic sampling technique was employed to reach the study subjects. In households with more than one eligible study subject, lottery was used to select only one child. When mother-child pairs were not available at the time of data collection, two repeated visits were made. Otherwise, the adjacent house was considered, though rarely.

\section{Data collection instruments and procedure}

Data were collected through a face to face interview by using a pretested and structured questionnaire. The questionnaire consisted of socio-demographic and economic characteristics, health, and dietary pattern related information. To maintain consistency, the questionnaire was first translated from English to Amharic, the native language of the study area, and was retranslated to English by professional translators. Two experienced public health experts and 12 trained data collectors ( 2 clinical optometrists and 10 clinical nurses) were recruited for supervision and data collection, respectively. The 
investigators coordinated the overall activities of data collection. The tool was piloted on 36 preschool children outside the study area. During the pre-test, the acceptability and applicability of the procedures and tools were evaluated. Household wealth index was computed using a composite indicator for urban and rural residents by considering properties like, livestock ownership, selected household assets, size of agricultural land, and the quantity of crop production. Principal component analysis (PCA) was performed to categorize the household wealth index into lowest, middle, and highest.

Height was measured using the seca vertical height scale (German, Serial No. 0123) standing upright in the middle of the board. The child's head, shoulders, buttocks, knees, and heels touch the vertical board. Nutrition related data were transferred to the ENA/SMART software version 2012 and hight-for-Age Z-scores (HAZ) was calculated using the WHO Multicenter Growth Reference Standard. Children were classified as undernourished if their $\mathrm{z}$ score was less than -2SD; otherwise, they were well-nourished ( $\geq-2 \mathrm{z}$ score). Accordingly, children were considered as stunted if their z-score of HAZ was below $-2 \mathrm{SD}$, respectively.

\section{Assessment of dietary diversity and quasi-food frequency}

Determination of the dietary diversity score (DDS) of a child was started by asking the mother to list all foods consumed by the child in the previous $24 \mathrm{~h}$ preceding the survey. In case of mixed dish, mothers were asked to list the ingredients of the food items. Then reported food items were classified into seven food groups, as starchy staples (grains, roots, and tubers); legumes, nuts and seeds; vitamin-A rich fruits and vegetables; other fruits and vegetables; egg; dairy products (milk, yoghurt, and cheese); and flesh foods (meat, fish, poultry, and organ meats) [23]. Considering four food groups as the minimum acceptable dietary diversity [24], a child with a DDS of less than four was classified as having poor dietary diversity; otherwise, they were considered to have good dietary diversity.

The seven-day quasi food frequency, modified food group frequency [2], was measured as the number of days the child consumed any of the vitamin-A rich foods in the last 7 days preceding the survey. Primarily, vitamin-A rich foods available in the study area were classified into plant-based (dark green leafy vegetables, other vitamin-A rich vegetables, and yellow orange fruits) and animal-based food groups (organ meat, eggs, and milk) [25]. Mothers were asked to report for how many days their children consumed any of the vitamin-A rich foods in the last 7 days. A score ranging from 1 to 7 was given depending on the number of days the child ate any of the above listed vitamin-A rich foods; otherwise, the score ' 0 ' was given if the child didn't eat any vitamin-A rich food. Hence, the above food groups constituted the six food groups which accounted for the maximum score of seven for each; the total score for the summary measure of quasi-food frequency was 42 .

\section{Clinical assessment of vitamin-A deficiency}

A detailed ophthalmic examination was carried out by clinical optometrists with a strict adherence to standard methods and procedures [26]. An ophthalmoscope, a pentorch, and magnifiers were used to identify the clinical signs of vitamin-A deficiency, such as Bitot's spot, conjunctival xerosis, corneal xerosis, corneal ulceration, and corneal scar. But, history of night blindness was confirmed by asking mothers using the local word for night blindness (dafint). Information on whether a child faced any difficulty while playing or in identifying objects in dim light, especially at sun set, was gathered.

\section{Data analysis}

Data were entered into EPI INFO version 3.5.3 and analyzed using the Statistical Package for Social Sciences (SPSS) version 20. Descriptive statistics, including frequencies and proportions were used to summarize the study variables. A binary logistic regression model was used to investigate factors associated with VAD. Variables with a $p$ values of $<0.2$ in the bivariable analysis were entered in the multivariable analysis to control the possible effect of confounders. The adjusted odds ratio (AOR) with a $95 \%$ confidence interval was estimated to assess the strength of association, and a $\mathrm{p}$ value of $<0.05$ was used to declare the statistical significance in the multivariable analysis. Furthermore the fitness of the model was checked using the Hosmer and lemeshow goodness of fit-test, and it was found as 0.68 .

\section{Results}

\section{Socio-demographic characteristics}

Six hundred eighty-one children were included in the study. The mean age $( \pm S D)$ of the children was 41.58 months $( \pm 11.27)$, and slightly more than half (53.6 \%) of them were male. Almost all (93.1\%) of the participants were living in the rural kebeles of Dembia District. In this community, nearly one-third (30\%) of the households (HHDs) had at least seven family members. The majority (95.4\%) of the mothers were housewives, uneducated $(77.1 \%)$, and gave their first birth before the age of 20 (63.1\%). Most (84.4\%) of the parents obtained food for household consumption from their own farm (own production) (Table 1).

\section{Health and nutrition related characteristics}

The majority ( $85.8 \%)$ of the mothers had at least one antenatal care (ANC) visit for the index child, but around 
Table 1 Socio-demographic characteristics of study participants in Dembia District, northwest Ethiopia, 2015

\begin{tabular}{|c|c|c|}
\hline Variables & Frequency & Percent \\
\hline \multicolumn{3}{|l|}{ Child age in month } \\
\hline $24-36$ & 288 & 42.3 \\
\hline $37-48$ & 233 & 34.2 \\
\hline $49-59$ & 160 & 23.5 \\
\hline \multicolumn{3}{|l|}{ Child sex } \\
\hline Male & 365 & 53.6 \\
\hline Female & 316 & 46.4 \\
\hline \multicolumn{3}{|l|}{ Residence } \\
\hline Urban & 47 & 6.9 \\
\hline Rural & 634 & 93.1 \\
\hline \multicolumn{3}{|l|}{ Marital status } \\
\hline Single & 25 & 3.7 \\
\hline Married & 613 & 90 \\
\hline Others $^{a}$ & 43 & 6.3 \\
\hline \multicolumn{3}{|l|}{ Religion } \\
\hline Orthodox & 674 & 99 \\
\hline Others $^{b}$ & 7 & 1 \\
\hline \multicolumn{3}{|l|}{ Ethnicity } \\
\hline Amhara & 673 & 98.8 \\
\hline Others $^{f}$ & 8 & 1.2 \\
\hline \multicolumn{3}{|l|}{ Household size } \\
\hline$\leq 4$ & 226 & 33.2 \\
\hline $5-6$ & 251 & 36.8 \\
\hline$\geq 7$ & 204 & 30.0 \\
\hline \multicolumn{3}{|c|}{ Number of children ever born } \\
\hline$\leq 2$ & 195 & 28.6 \\
\hline $3-5$ & 355 & 52.1 \\
\hline$\geq 6$ & 131 & 19.2 \\
\hline \multicolumn{3}{|l|}{ Birth order } \\
\hline $1 \mathrm{st}$ & 128 & 18.8 \\
\hline 2nd-4th & 362 & 53.2 \\
\hline$\geq 5$ th & 191 & 28 \\
\hline \multicolumn{3}{|l|}{ Maternal education } \\
\hline Uneducated & 525 & 77.1 \\
\hline Primary & 58 & 8.5 \\
\hline Secondary and above & 98 & 14.4 \\
\hline \multicolumn{3}{|l|}{ Maternal employment } \\
\hline Housewife & 650 & 95.4 \\
\hline Others $^{c}$ & 31 & 4.6 \\
\hline \multicolumn{3}{|l|}{ Maternal age } \\
\hline $15-34$ & 495 & 72.7 \\
\hline $35-48$ & 186 & 27.3 \\
\hline \multicolumn{3}{|l|}{ Mothers age at first birth } \\
\hline$\leq 19$ & 430 & 63.1 \\
\hline $20-39$ & 251 & 36.9 \\
\hline \multicolumn{3}{|l|}{ Paternal education } \\
\hline Uneducated & 410 & 60.2 \\
\hline Educated & 271 & 39.8 \\
\hline
\end{tabular}

Table 1 continued

\begin{tabular}{|c|c|c|}
\hline Variables & Frequency & Percent \\
\hline \multicolumn{3}{|c|}{ Paternal employment } \\
\hline Farmer & 620 & 91 \\
\hline Merchant & 32 & 4.7 \\
\hline Others $^{d}$ & 29 & 4.3 \\
\hline \multicolumn{3}{|l|}{ Wealth status } \\
\hline Poor & 226 & 33.2 \\
\hline Middle & 228 & 33.5 \\
\hline High & 227 & 33.3 \\
\hline \multicolumn{3}{|l|}{ Supported by PSNP } \\
\hline Yes & 41 & 6.0 \\
\hline No & 640 & 94.0 \\
\hline \multicolumn{3}{|c|}{ Model household graduate } \\
\hline Graduated & 285 & 41.9 \\
\hline Not graduated & 396 & 58.1 \\
\hline \multicolumn{3}{|c|}{ Main source of family food } \\
\hline Own production & 575 & 84.4 \\
\hline Other & 106 & 15.6 \\
\hline \multicolumn{3}{|c|}{ Vegetable production } \\
\hline Yes & 108 & 15.9 \\
\hline No & 573 & 84.1 \\
\hline \multicolumn{3}{|l|}{ Fruit production } \\
\hline Yes & 33 & 4.8 \\
\hline No & 648 & 95.2 \\
\hline
\end{tabular}

a Divorced, widowed and separated

${ }^{b}$ Muslim and protestant

c Merchant, government employ and student

d Government employ and daily laborer

e Purchasing and family assistant

f Oromo and Tigre

one third (29.9 \%) gave birth at heath facilities. A substantial number (92.4\%) of the children took vitamin-A supplementation in the last 6 months. Most $(82.5 \%)$ of the children had a dietary diversity score of below 4 . Only a few children ate meat $(0.6 \%)$, eggs $(0.3 \%)$, and vitamin-A rich fruits and vegetables $(0.6 \%)$ in the previous 24-h (Fig. 1). Furthermore, about $36 \%$ of them ate any of vitamin-A rich food in the last 7 days preceding the survey. Nearly three-fourths $(70.3 \%)$ of the mothers initiated breast feeding in a timely fashion, within an hour of delivery, and a significant proportion of the mothers $(65.9 \%)$ initiated complementary feeding at the 6 month (Table 2).

\section{Prevalence of vitamin-A deficiency}

The overall prevalence of xerophthalmia was $8.6 \%$ [95\% CI 6.6,11\%]. In the following diagram each specific type was summarized (Fig. 2). 


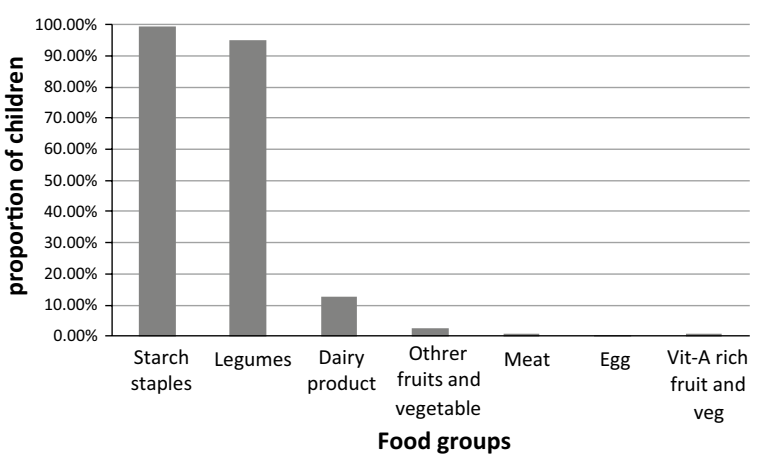

Fig. 1 Proportion of preschool children who consumed food groups in the previous 24-h preceding the survey, Dembia District, northwest Ethiopia, 2015

Factors associated with vitamin-A deficiency

In both the bivariable and multivariable analyses, sex and age of the child and the ANC follow up were significantly associated with VAD. Accordingly, being a male child increases the odds of developing VAD 1.81 times [AOR $1.81,95 \%$ CI 1.01,3.24]. Likewise, increased odds of VAD were noted among children aged 49-59 months [AOR 3.00, $95 \%$ CI 1.49,6.02] and whose mothers had no ANC visit [AOR 2.65, 95 \% CI 1.39,5.07] (Table 3).

\section{Discussion}

In this study, in spite of intensive nutritional interventions, the prevalence of Xerophthalmia still remains unacceptably high, five times higher than the WHO cut-off point for public health significance (1.56\%) [27]. This might be related to the lower rate of maternal literacy in the study area $(22.9 \%)$. Maternal literacy is a strong predictor of good childhood nutritional outcome, mainly through creating a fertile ground for adoption of scientifically supported child feeding practices [28, 29]. Moreover, poor dietary intake of vitamin-A rich food is an important predictor of VAD [9, 30, 31]. Thus, the higher burden of xerophthalmia in the area could also be attributed to poor dietary intake of vitamin-A rich food. Nearly two-thirds (64.3\%) of the children didn't eat any of the vitamin-A rich foods in the last 7 days preceding the survey, indicating a higher vulnerability of the children to VAD $[26,27]$.

This prevalence was also the highest of any study reporting from developing countries, such as Nigeria (1.1\%) [32] and rural India (2.3\%) [12]. This huge discrepancy could be partially explained by the socio-economic and cultural differences of the study areas.

Children aged 49-59 months were more likely to suffer from VAD as compared to children who were between 24 and 36 months of age. Similar findings were reported in Sudan [33] and India [34]. This is probably due to the fact
Table 2 Health and nutrition related characteristics of study participants in Dembia District, northwest Ethiopia, 2015

\begin{tabular}{|c|c|c|}
\hline Variables & Frequency & Percent \\
\hline \multicolumn{3}{|l|}{ ANC visit } \\
\hline Yes & 584 & 85.8 \\
\hline No & 97 & 14.2 \\
\hline \multicolumn{3}{|l|}{ Place of delivery } \\
\hline Home & 480 & 70.5 \\
\hline Health facility & 201 & 29.5 \\
\hline \multicolumn{3}{|c|}{ Initiation of breastfeeding } \\
\hline Early initiation & 479 & 70.3 \\
\hline Late initiation & 202 & 29.7 \\
\hline \multicolumn{3}{|l|}{ Prelacteal feeding } \\
\hline Yes & 344 & 50.5 \\
\hline No & 337 & 49.5 \\
\hline \multicolumn{3}{|c|}{ Complementary food initiation } \\
\hline Timely & 449 & 65.9 \\
\hline Early & 33 & 4.8 \\
\hline Late & 199 & 29.2 \\
\hline \multicolumn{3}{|l|}{ Dietary diversity } \\
\hline$<4$ & 562 & 82.5 \\
\hline$\geq 4$ & 119 & 17.5 \\
\hline \multicolumn{3}{|l|}{ Quasi food frequency } \\
\hline Zero & 438 & 64.3 \\
\hline $1-3$ & 137 & 20.1 \\
\hline$\geq 4$ & 106 & 15.6 \\
\hline \multicolumn{3}{|c|}{ Vitamin-A supplementation } \\
\hline Yes & 629 & 92.4 \\
\hline No & 52 & 7.6 \\
\hline \multicolumn{3}{|l|}{ Immunization status } \\
\hline Partially immunized & 121 & 17.8 \\
\hline Fully immunized & 560 & 82.2 \\
\hline \multicolumn{3}{|c|}{ Any morbidity in the last 2 week } \\
\hline Yes & 108 & 15.9 \\
\hline No & 573 & 84.1 \\
\hline \multicolumn{3}{|l|}{ Stunting } \\
\hline Yes & 313 & 46 \\
\hline No & 368 & 54 \\
\hline
\end{tabular}

that this age category is the turning point for increased energy and micronutrient requirements compared to younger children, to support their rapid growth and development $[35,36]$. Though their physiological state calls for extra nutritional requirement, only few children consumed vitamin-A rich complementary food in the current study area and in the country at large [28]. This extra micronutrient requirement coupled with poor dietary intake might worsen the risk of developing VAD in older children.

The current study also found that male children were at higher risk of developing vitamin-A deficiency. This 


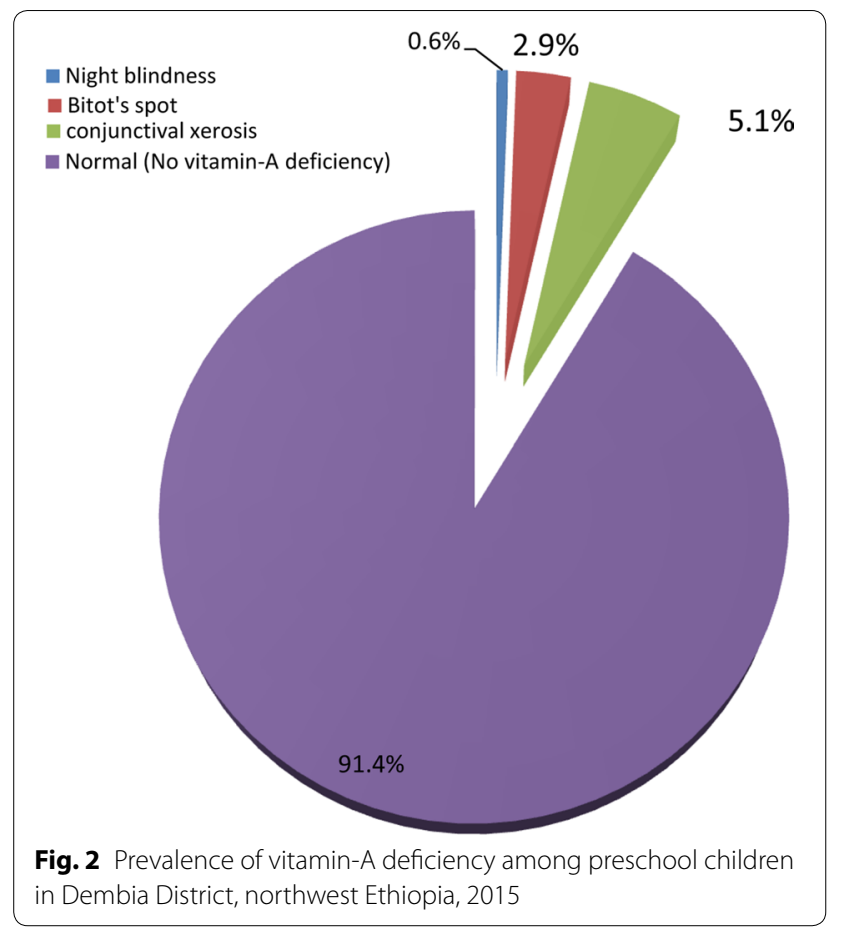

finding was supported by reports from Israel [11] and India [34]. However a different finding was reported by another study in Ethiopia [37]. This might be related to the slightly higher nutritional requirement of male children for vitamin-A [38]. The other possible explanation could be related to diarrheal diseases, as most male children $(89.8 \%)$ experienced fever and diarrhea in this study. According to some reports, fever is mostly associated with the commonest childhood illness of infectious origin, such as diarrhea, malaria, and respiratory tract infection. Febrile illness during childhood could result in decreased food intake and malabsorption of nutrients, such as vitamin-A. It is also confirmed that, the above highly common childhood infectious diseases are significant determinants of VAD [10, 31, 39]. However, the relationship between child sex and risk of VAD needs further investigation.

The third important factor associated with VAD was ANC follow up. Children whose mothers had no ANC follow up were more likely to suffer from VAD. ANC is an ideal entry point for providing nutritional care and counseling [40] and to promote the benefit of institutional delivery $[41,42]$. Proper nutritional counseling and support helps to enhance nutritional knowledge and appropriate dietary habit of pregnant mothers [43]. ANC also steps-up the likelihood of receiving the child and maternal postnatal vitamin-A supplementation [44]. This in
Table 3 Factors associated with vitamin-A deficiency among preschool children in Dembia District, northwest Ethiopia, 2015

\begin{tabular}{|c|c|c|c|c|}
\hline \multirow[t]{2}{*}{ Variables } & \multicolumn{2}{|c|}{ Vitamin-A deficiency } & \multirow{2}{*}{$\begin{array}{l}\text { COR } \\
(95 \% \mathrm{Cl})\end{array}$} & \multirow{2}{*}{$\begin{array}{l}\text { AOR } \\
(95 \% \mathrm{Cl})\end{array}$} \\
\hline & Yes\# (\%) & No\# (\%) & & \\
\hline \multicolumn{5}{|l|}{ Child sex } \\
\hline Male & 40 (11\%) & $325(89 \%)$ & $\begin{array}{l}1.92 \\
(1.09,3.39)\end{array}$ & $1.81(1.01,3.24)$ \\
\hline Female & $19(6 \%)$ & $297(94 \%)$ & 1 & 1 \\
\hline \multicolumn{5}{|c|}{ Wealth status } \\
\hline Poor & $17(7.5 \%)$ & 209 (92.5 \%) & $\begin{array}{l}0.66 \\
\quad(0.35,1.25)\end{array}$ & \\
\hline Middle & $17(7.5 \%)$ & $211(92.5 \%)$ & $\begin{array}{l}0.65 \\
(0.34,1.24)\end{array}$ & \\
\hline High & 25 (11\%) & $202(89 \%)$ & 1 & \\
\hline \multicolumn{5}{|c|}{ Child age in month } \\
\hline $24-36$ & $16(5.6 \%)$ & $272(94.4 \%)$ & 1 & 1 \\
\hline $37-48$ & $20(8.6 \%)$ & $213(91.4 \%)$ & $\begin{array}{l}1.59 \\
(0.81,3.16)\end{array}$ & $1.57(0.78,3.17)$ \\
\hline $49-59$ & $23(14.4 \%)$ & $137(85.6 \%)$ & 2.85 & $3.00(1.49,6.02)$ \\
\hline
\end{tabular}

\section{Place of delivery}

$$
\begin{array}{llll}
\text { Home } & 46(9.6 \%) & 434(90.4 \%) & 1 \\
\text { Health } & 13(6.5 \%) & 188(93.5 \%) & 0.65
\end{array}
$$$$
\text { facility } \quad(0.34,1.24)
$$

Model household

$\begin{array}{lllll}\text { Yes } & 20(7 \%) & 265(93 \%) & 0.69 \\ & & (0.39,1.21) \\ \text { No } & 39(9.8 \%) & 257(90.2 \%) & 1 \\ \text { No } & & \\ \text { Quasi food frequency } & & \\ \text { Zero } & 44(10 \%) & 394(90 \%) & 1.58 \\ & & (0.69,3.61) & \\ 1-3 & 8(5.8 \%) & 129(94.2 \%) & 0.88(0.31,2.5) \\ \geq 4 & 7(6.6 \%) & 99(93.4 \%) & 1 & \\ \text { Antenatal care } & & & & 1 \\ \text { Yes } & 42(7.2 \%) & 542(92.8 \%) & 1 & 2.65(1.39,5.07) \\ \text { No } & 17(17.5 \%) & 80(82.5 \%) & 2.74 & (1.49,5.05)\end{array}$

Vegetable production

$$
\begin{array}{llrc}
\text { Yes } & 13(12 \%) & 95(88 \%) & 1.57 \\
\text { No } & 46(8 \%) & 527(92 \%) & 1
\end{array}
$$

Main source of family food

$$
\begin{array}{cccc}
\begin{array}{c}
\text { Own pro- } \\
\text { duction }
\end{array} & 54(9.4 \%) & 521(90.6 \%) & 1 \\
\text { Other } & 5(4.7 \%) & 101(95.3 \%) & \begin{array}{c}
0.48(0.19, \\
1.22)
\end{array}
\end{array}
$$

Number of children ever born

$$
\begin{array}{llll}
\leq 2 & 21(10.8 \%) & 174(89.2 \%) & \begin{array}{l}
2.57 \\
(0.97,6.41)
\end{array} \\
3-5 & 32(9.0 \%) & 323(91 \%) & 2.06 \\
& & & (0.84,5.06) \\
\geq 6 & 6(4.6 \%) & 125(95.4 \%) & 1
\end{array}
$$


turn could help to improve maternal vitamin-A reserve for later lactation. Additionally, ANC with a profound effect of institutional delivery helps to promote exclusive and early initiation of breastfeeding [45, 46], commonly advocated public health measures to avert childhood VAD $[13,28]$.

This study tried to show the burden of vitamin-A deficiency in preschool children, which has not been well investigated before in the study area. The investigators also made a lot of effort to maintain the quality of the data, mainly through a pretest, frequent field supervisions, and training of data collectors. However, the study was not free from limitations. First, since dietary assessments were made through recall (with the longest recall period of 7 days in case of the seven-day quasi-frequency), there might have been a risk of recall bias. Secondly, the study didn't consider the measurement of the serum retinol level and estimation of the portion size of food intake. Thirdly, the study was not free from the pitfalls of a cross-sectional study design.

\section{Conclusions}

Vitamin-A deficiency has severe public health significance in the study area. Strengthening the utilization of antenatal care and giving special emphasis to preschool children helps to mitigate vitamin-A deficiency.

\begin{abstract}
Abbreviations
WHO: World Health Organization; AOR: adjusted odds ratio; Cl: confidence interval; COR: crude odds ratio; ANC: antenatal care (ANC); VAD: vitamin-A deficiency; DDS: dietary diversity score; HHDs: households; WHZ: weight-forhight Z-scores; HAZ: hight-for-age Z-scores.
\end{abstract}

\section{Authors' contributions}

AT conceived and designed the study, performed statistical analysis, coordinated the data collection activities, and drafted the manuscript. AF participated in designing the study, coordinated the data collection activities, and participated in drafting the manuscript. ATF participated in designing the study and drafted the manuscript. SM participated in statistical analysis and writing of the manuscript. All authors read and approved the final manuscript.

\section{Author details}

${ }^{1}$ Department of Human Nutrition, Institute of Public Health, College of Medicine and Health Sciences, The University of Gondar, Gondar, Ethiopia. ${ }^{2}$ Department of Epidemiology and Biostatistics, Institute of Public Health, College of Medicine and Health Sciences, The University of Gondar, Gondar, Ethiopia. ${ }^{3}$ Department of Optometry, School of Medicine, College of Medicine and Health Sciences, The University of Gondar, Gondar, Ethiopia.

\section{Acknowledgements}

Authors would like to thank mothers for their willingness to participate in the study. The authors appreciation will also go to the university of Gondar for provision of financial support as well as to Dembia District Health Office for their positive co-operation and providing materials.

\section{Competing interests}

The authors declare that they have no competing interests.

\section{Availability of data and materials}

Data will be made available up on request from the primary author.

\section{Consent to publish}

Not applicable.

\section{Ethics approval and consent to participate}

Ethical clearance was obtained from the Institutional Review Boards of the University of Gondar. An official permission letter was secured from Dembia District Health Office. All mothers or caretakers of children were informed about the purpose of the study, and interviews were held only with those who agreed to give a written consent to participate. Uneducated mothers affirmed their consent by their thumb print. The right of a participant to withdraw from the study at any time, without any precondition was disclosed unequivocally. Moreover, the confidentiality of information obtained was guaranteed by all data collectors and investigators by using code numbers rather than personal identifiers and by keeping the questionnaire locked. Children with any clinical signs of xerophthalmia were treated immediately with 200, 000 IU vitamin A on days 1, 2 and 7 after ocular examination.

Received: 16 April 2016 Accepted: 21 June 2016

Published online: 24 June 2016

\section{References}

1. WHO. Global prevalence of vitamin A deficiency in populations at risk 1995-2005. WHO global database on vitamin A deficiency. Geneva: World Health Organization; 2009.

2. Arimond M, Ruel MT. Progress in developing an infant and child feeding index: an example using the Ethiopia demographic and health survey 2000. International Food Policy Research Institute Washington, DC; 2002.

3. West KP. Extent of vitamin A deficiency among preschool children and women of reproductive. J Nutr. 2002;132:2857S-2866S.

4. West KP, Mehra S. Vitamin A intake and status in populations facing economic stress. J Nutr. 2009;140:201.

5. Rice A, West K, Black R, Ezzati M, Lopez A, Rodgers A, Murray C. Comparative quantification of health risks: global and regional burden of disease attributable to selected major risk factors, vol. 1. Geneva: World Health Organization; 2004.

6. Levels and trends in child mortality. Geneva: World Health Organization; 2012.

7. Kello AB, Gilbert C. Causes of severe visual impairment and blindness in children in schools for the blind in Ethiopia. Br J Ophthalmol. 2003;87:526-30.

8. Demissie T, Ali A, Mekonnen Y, Haider J, Umeta M. Demographic and health-related risk factors of subclinical Vitamin A deficiency in Ethiopia. J Health Popul Nutr. 2009;27:666.

9. Gebreselassie SG, Gase FE, Deressa MU. Prevalence and correlates of prenatal vitamin A deficiency in rural Sidama, Southern Ethiopia. J Health Popul Nutr. 2013;31(2):185-94.

10. Sachdeva S, Alam S, Beig FK, Khan Z, Khalique N. Determinants of vitamin A deficiency amongst children in Aligarh District, Uttar Pradesh. Indian Pediatr. 2011;48(17):853-4.

11. Coles C, Levy A, Gorodischer R, Dagan R, Deckelbaum R, Blaner W, Fraser D. Subclinical vitamin A deficiency in Israeli-Bedouin toddlers. Eur J Clin Nutr. 2004;58:796-802.

12. Laxmaiah A, Nair MK, Arlappa N, Raghu P, Balakrishna N, Rao KM, Galreddy C, Kumar S, Ravindranath M, Rao W, et al. Prevalence of ocular signs and subclinical vitamin A deficiency and its determinants among rural preschool children in India. Public Health Nutr. 2010;15(4):568-77.

13. WHO. Indicators for assessing infant and young child feeding practices Part 1: definitions; 2008.

14. Haidar J. Common micronutrient deficiencies among food aid beneficiaries: evidence from refugees in Ethiopia. Ethiop J Health Dev. 2001;25(3):222.

15. Kassaye T, Receveur O, Johns T, Becklake MR. Prevalence of vitamin A deficiency in children aged 6-9 years in Wukro northern Ethiopia. Bull World Health Organ. 2001;79(5):415.

16. Mekuria G, Edris M. Exclusive breastfeeding and associated factors among mothers in Debre Markos, Northwest Ethiopia: a cross-sectional study. BMC Int Breastfeed J. 2015;10(1):1. 
17. Adugna DT. Women's perception and risk factors for delayed initiation of breastfeeding in Arba Minch Zuria, Southern Ethiopia. Int Breastfeed J. 2014;9:8.

18. Grantham-McGregor S, Cheung YB, Cueto S, Glewwe P, Richter L, Strupp B. Developmental potential in the first 5 years for children in developing countries. Lancet. 2007;369:60-70.

19. Jones G. How many child deaths can we prevent this year? Lancet. 2003;5:362.

20. A strategy for acceleration of progress in combating vitamin A deficiency. United Nations Children's Fund (UNICEF) in association with: The Micronutrient Initiative (MI) and The World Health Organization (WHO), New York; 1997. p. 18-19.

21. Amhara: Ethiopia Demographic and Health: http://www.etharc.org/ Amhara/About\%20Us/Geography.htm. 2008.

22. Ethiopia: Iivelihood profile Amhara Region, Ethiopia Tana Zuria Livelihood Zone (TZA). 2007.

23. Organization $\mathrm{WH}$ : indicators for assessing infant and young child feeding practices. 2008 (ISBN 9789241596664 ).

24. Organization WH: indicators for assessing infant and young child feeding practices Part 1 Definitions. Food and nutrition technical assitance November 2007.

25. Kennedy G, Ballard T, Dop M. Guidelines for measuring household and individual dietary diversity. Nutrition and Consumer Protection Division, Food and Agriculture Organization of the United Nations. 2011.

26. Sommer A. Vitamin-A deficiency and its consequence fiend guide to detection and control. 3rd ed. Geneva: World Health Organization; 1995.

27. World Health Organization: indicators for assessing vitamin-A deficiency and their implications in monitoring and evaluating intervention programs, Geneva: micronutrient series 1995

28. Central Statistical Authority (Ethiopia) and ORC Macro: Ethiopia Demographic and Health Survey 2011. Addis Ababa; 2011.

29. Woldie H, Kebede Y, Tariku A. Factors associated with anemia among children aged 6-23 months attending growth monitoring at Tsitsika Health Center, Wag-Himra Zone, Northeast Ethiopia. J Nutr Metab. 2015:2014:2948.

30. Akhtar S, Ahmed A, Randhawa MA, Atukorala S, Arlappa N, Ismail T, Ali Z. Prevalence of vitamin A deficiency in South Asia: causes, outcomes, and possible remedies. J Health Popul Nutr. 2013;31(4):413-23.

31. Sole GD, Belay Y, Zegeye B. Vitamin A deficiency in southern Ethiopia. Am J Clin Nutr. 1987:45:780-4.

32. Ajaiyeoba Al. Vitamin A deficiency in nigerian children. Afr J Biomed Res. 2002:4:3.
33. Rostami N, Farsar A, Shiba N. Prevalence of sub-clinical vitamin-A deficiency in 2-5 years old children in Tehran. East Meditterr Health J. 2007:13(2):273

34. Arlappa N, Balakrishna N, Laxmaiah A, Nair KM, Brahmam G. Prevalence Of clinical and sub-clinical vitamin a deficiency among rural preschool children of West Bengal India. Indian Pediatr. 2011;48:47.

35. Carolyne DB. Advanced nutrition micronutrient. USA; 1998.

36. Whiteny E, Rolfes Sr. Understanding nutrition. 11th ed. USA; 2008

37. Moore DB, Shirefaw W, Tomkins-Netzer O, Eshete Z, Netzer-Tomkins H, Ben-Zion I. Prevalence of xerophthalmia among malnourished children in rural Ethiopia. Int Ophthalmol. 2013:33:455-9.

38. World Health Organization and Food and Agriculture Organization of the United Nations; Vitamin and mineral requirements in human nutrition: report of a joint FAO/WHO expert consultation, Bangkok, Thailand, 21-30 September 1998. 2nd ed. Rome; 2004

39. Thornton KA, Mora-Plazas M, Mar'ın C, Villamor E. Vitamin A deficiency is associated with gastrointestinal and respiratory morbidity in school-age children. J Nutr Nutritional Epidemiol. 2014;144:496-503.

40. USAID/Access to clinical and community maternal nawhs: focused antenatal care: providing integrated, individualised care during pregnancy. 2004.

41. Teferra AS, Alemu FM, Woldeyohannes SM. Institutional delivery service utilization and associated factors among mothers who gave birth in the last 12 months in Sekela District, North West of Ethiopia: a communitybased cross sectional study. BMC Pregnancy Childbirth. 2012;12:74

42. Varma D, Khan ME, Hazra A. Increasing institutional delivery and access to emergency obstetric care services in rural Uttar Pradesh. J Fam Welf. 2010;56:23.

43. Daba G, Beyene F, Fekadu H, Garoma W. Assessment of knowledge of pregnant mothers on maternal nutrition and associated factors in Guto Gida Woreda, East Wollega Zone, Ethiopia. J Nutr Food Sci. 2013;3:235.

44. Haile D, Biadgilign S, Azage M. Differentials in vitamin A supplementation among preschool-aged children in Ethiopia: evidence from the 2011 Ethiopian demographic and health survey. Public health. 2015;129(6):748-54.

45. Seid AM, Yesuf ME, Koye DN. Prevalence of exclusive breastfeeding practices and associated factors among mothers in Bahir Dar city, Northwest Ethiopia: a community based cross-sectional study. Int Breastfeed J. 2013:8:14

46. Yalew WA, Abitew DB. Breastfeeding practices of mothers of under 5 years old children in bahir dar city, ethiopia: a descriptive cross sectional community based survey. Int J Med Sci Public Health. 2014;3(5):532-6.

\section{Submit your next manuscript to BioMed Central and we will help you at every step:}

- We accept pre-submission inquiries

- Our selector tool helps you to find the most relevant journal

- We provide round the clock customer support

- Convenient online submission

- Thorough peer review

- Inclusion in PubMed and all major indexing services

- Maximum visibility for your research

Submit your manuscript at www.biomedcentral com/submit
BioMed Central 